\title{
Exit, Voice, Loyalty and Neglect as Student Responses to Dissatisfaction: An Act Frequency Approach
}

\author{
Tom Mahaffey ${ }^{\star}$, Dean Neut, and Alison Taylor ${ }^{\Delta}$
}

\begin{abstract}
An important task in higher education is the provision of an abstract theoretical model capable of integrating various student responses to dissatisfaction. Drawing upon recent work in the social sciences, we propose exit, voice, loyalty and neglect (EVLN) as a parsimonious means of understanding the relationships among the different responses to dissatisfaction. We use an act frequency approach to develop and validate the EVLN constructs as a preliminary first step toward future predictive theory.
\end{abstract}

\section{RÉSUMÉ}

La définition d'un modèle théorique abstrait capable d'intégrer les différentes réactions de mécontentement des étudiants est une tâche importante dans le domaine de l'enseignement supérieur. En nous appuyant sur des recherches récentes en sciences sociales, nous proposons "sortie, voix, loyauté et manque d'attention" comme moyen parcimonieux pour comprendre les relations entre les différentes réactions de mécontentement. Nous utilisons une approche de fréquence d'actions pour élaborer et valider les concepts de "sortie, voix, loyauté et manque d'attention", ce qui constitue un premier pas vers une théorie prédictive future.

\footnotetext{
* St. Francis Xavier University

$\dagger$ University of Calgary

$\Delta$ Ontario Institute for Studies in Education
}

The authors would like to thank all those who helped administer the various questionnaires. The paper benefited from discussions with Bill Cooper, Lorraine Dyke and Bob Wilson. The paper also benefited from comments received during presentation of an earlier version at the 1989 annual CSSE meetings and from the CJHE reviewers. SSHRC funding provided to the first two authors is also gratefully acknowledged. Finally, the usual absolutions apply. 
Student responses to dissatisfying conditions take many forms. Some students drop out altogether. Others only stop going to class. Some students voice their concerns by running for student government, while yet others quietly resolve to work that much harder.

Researchers have addressed the issue of student dissatisfaction in a number of studies. For example, McCutcheon and Beder (1987) looked at the causes of absenteeism among college students. Researchers have also examined the significance of student voice mechanisms (cf Diener, 1973). Other researchers (cf Bean, 1980, 1983; Brigman and Stagner, 1979; Winteler 1987) have studied dropouts, stopouts and transfers, finding that a variety of personal, social and institutional factors influence students' responses. What is notable about much of this research is the treatment of various student responses to dissatisfaction as separate phenomena. As yet unexamined is the notion that absenteeism, dropouts, transfers, activism and even stoic resignation may all be internally related. As a result, previous studies do not help us to understand the interrelationships among student responses to dissatisfaction or why one student may voice his/her displeasure while another, when faced with an identical stimulus, may gradually withdraw from the source of dissatisfaction and eventually drop out.

Exit, Voice, Loyalty, and Neglect (EVLN) has been suggested as a parsimonious and yet integrated means of looking at responses to dissatisfying situations (Rusbult, Zembrodt and Gunn, 1982). EVLN has been used to study topics as diverse as romantic relationships (Rusbult, Zembrodt and Gunn, 1982) and employee dissatisfaction (Farrell, 1983; Mahaffey and Neu, 1988; Withey \& Cooper, 1989). In the context of education, EVLN would incorporate dropout (as a form of exit) and absenteeism (as a form of neglect) as expressions of dissatisfaction while recognizing that other responses such as joining student government (voice) are also possible.

An increased understanding of student responses to dissatisfaction is of interest to a wide-ranging audience both because of the financial costs associated with attrition (Langer et al, 1987; State University of New York, 1987) as well as the personal costs that accrue to students, their families and friends.

An identification of the determinants of differential responses to dissatisfaction provides a starting point for institutional action. This action may take the form of student counselling, the provision of a variety of retention enhancing strategies or the alleviation of institutional sources of dissatisfaction. EVLN may thus prove useful as an integrated way of studying the variety of student responses to dissatisfying educational situations. 
The purpose of this paper is to develop the domain of the EVLN constructs as a necessary prelude to further EVLN research. An act-frequency approach (Buss \& Craik, 1983, 1985) is used to develop the measures. The following section briefly reviews the EVLN model. Next, the act-frequency approach to construct development is examined and the measurement process is discussed. Finally, concluding comments are provided.

\section{The EVLN Model}

The notions of Exit, Voice and Loyalty were developed by Hirschman (1970) to explain the responses of states, firms and individuals to deteriorating situations. Hirschman's interest lay in the identification of "repairable lapses in an institution's performance" (p.l). The manner in which the institution's membership responds to these various lapses is a valuable source of management intelligence by means of which administrators learn of organizational deficiencies. According to Hirschman, judicious attention to expressions of dissatisfaction could prevent further performance erosion.

In declining situations, Hirschman suggested that individuals choose from among three possible courses of action. Some individuals choose to move away from the source of dissatisfaction (exit). The exit option was posited to be a very effective means of alerting an institution's administration to the fact that something was amiss. And while attrition has always represented a significant personal cost to the individuals involved, declining enrolments and an increased need to grapple with student retention have recently made the various responses to dissatisfaction a concern to administrators, as well.

Other individuals attempt to change dissatisfying situations (voice) rather than moving away from them (p. 30). Voice is a political response to dissatisfaction that under certain specified conditions is also hypothesized to mediate exit. For example, when investment is high and alternatives are expensive, voice would normally precede exit (March and Simon, 1958).

Finally, some individuals will remain with the organization (loyalty) hoping that someone else will act or that something will happen to improve matters (p.78). Loyalist responses to dissatisfaction are highly desirable from the perspective of most organizations, especially if the decline giving rise to the dissatisfaction is temporary. Loyalty can be both an independent response to dissatisfaction and a transition between exit and voice.

A fourth dimension--neglect-was subsequently added to Hirschman's EVL model (Rusbult, Zembrodt and Gunn, 1982). According to Rusbult and colleagues, neglect occurs when individuals neither try to improve their 
situation nor expect that someone else will improve it for them. For Rusbult et al (1982), neglect is manifested in generally inattentive behaviour, such as not caring or staying away.

These broad theory driven conceptualizations provided the starting point for developing specific measures for each of the constructs. Based on nominations carried out in the first phase of the research and described fully in the next section, each of the constructs was defined. Exit was defined to mean taking steps to leave the institution, up to and including actually withdrawing from school permanently. Voice was defined as taking action to change the situation at school or in residence, including working with others. Loyalist behaviour was defined as supporting one's residence, school etc., including both active and passive support. Finally, neglect was defined to be a failure to meet one's obligations as a student including actions that were dysfunctional to the student and/or the institution.

\section{Methodology}

An act-frequency approach (AFA) was used to develop the EVLN constructs. An AFA is increasingly used as a measure development method within personality theory research (Buss and Craik 1983, 1985). Dispositions function as "natural cognitive categories with acts as members" (1985, p.105). For example, we infer that a person is generous by observing that person's specific behaviours. The frequency aspect involves specifying the incidence of acts over time. The boundaries between disposition categories are "fuzzy" ((Zadeh, Fu, Tanaka and Shimura, 1975) and acts within each category differ in their centrality of membership (Rosch, 1975; Rosch and Mervis, 1975).

Specific behaviours were viewed by Rosch and her colleagues as having different within-category status. The internal cognitive structure of the disposition meant that one could distinguish better examples of a disposition from poorer examples. Hence, only the most prototypical acts are used to form the domain of the category. Categories are called fuzzy because the boundaries between categories, where the less prototypical acts are found, are not sharply drawn and hence one category (such as neglect) may blend into an adjacent category (such as exit).

Use of the AFA to develop a measure of student responses to dissatisfaction has three important features to recommend it. First, it is highly contextual in that it begins with the experiences of this target population and will subsequently be used with this same population. In fact, students comprise the samples in all three phases of the instrument development. Therefore, we 
anticipate that the resulting instrument will be more valued than instruments developed without the assistance of the target population. Second, the AFA seeks to identify behaviours, rather than attitudes. Attitude instruments are more ambiguous and hence less likely to attain predictive validity, despite their use in previous research (cf Cullers, Hughes and McGreal, 1973; Steele, 1978). In addition, behavioural measures are more amenable to triangulation using external observers in addition to the study participant, thereby mitigating problems associated with sole reliance on self-report data. This emphasis on behaviours as opposed to attitudes and motivations helps differentiate the AFA from the domain-sampling approach to construct development (Block, 1989).

Finally, it is likely that the constructs of exit, voice, loyalty and neglect encompass acts that can be cognitively grouped together. The boundaries between these categories are likely to overlap somewhat (Mahaffey and Neu, 1988), with certain acts belonging to more than one category. In fact, in the original model (Hirschman, 1970), the constructs were not conceived as mutually exclusive. Notions of prototypicality and "fuzziness" therefore appear to be particularly appropriate. The application of act frequency to EVLN responses to student dissatisfaction thus appears to be both grounded in the underlying theory and methodologically sound.

An AFA to measurement development consists of three phases (Buss and Craik, 1985):

1) Act nominations;

2) Composite consensus of prototypicality judgments;

3) Multiple-dispositional act sorting.

The following sections discuss this approach in the development of EVLN measures.

\section{Phase 1: Act Nominations}

In this phase, nominators were asked to "recall specific manifestations that fall within the category boundaries of a given disposition" (Buss \& Craik, 1985:937). Specifically, nominators were provided with the following instructions for suggesting possible exit acts:

Try to think of some students that you have known. With these individuals in mind, please describe five (or more) EXIT acts or behaviors that they engaged in when they were dissatisfied.

Two of the four EVLN constructs were randomly assigned to each nominator. Their nominations served two purposes. First, they defined the potential domain of acts within each category that was used in later measure 
development stages. Second, the number of acts that were nominated provided an indication of the volume of the construct domain. Care was taken to ensure that only non-trivial differences in the nominations were treated as separate acts (Block, 1989).

The nominating group consisted of 30 individuals selected from among students (undergraduate and graduate), faculty and counsellors. The nominators were from different programs and faculties at a mid-sized university. This nominating procedure yielded an average of 80 different acts in each of the EVLN categories. These acts were edited, to ensure similar form only, in preparation for the second phase of the research.

\section{Phase 2: Composite Consensus of Prototypicality Judgments}

In this phase, a separate panel of judges was asked to rate each act generated by the nominators in terms of its prototypicality (the clearest case or best example). Raters judged the prototypicality of all acts within a category using a 7-point scale where 7 is most prototypical and 1 is least prototypical.

In contrast to the first phase, judges in this phase were necessarily provided with definitions of the construct they were judging to ensure that the semantic meaning of the terms was the same for all judges. Instructions to the nominators during the first phase on the other hand, were kept purposefully vague so that researcher preconceptions did not prematurely place boundaries upon the parameters of the construct (Buss and Craik, 1985). This feature of the AFA, while giving highly grounded results, comes at the expense of significant effort on the part of the nominators who must begin the definitional process, alone.

It was on the basis of the nominated acts that definitions were settled upon. It was these definitions which were used for the protypicality ratings. For example, judges rating the prototypicality of neglectful acts were provided with the following specific definition:

The purpose of this study is to find out what prototypical acts students have in mind when they talk about neglect. By neglect I mean failing to meet one's obligations as a student including actions dysfunctional to the student and/or institution. [Judges were also provided with standardized instructions for assessing what is meant by "prototypicality"].

Similarly, judges ranking the other constructs were provided with the construct definitions previously discussed.

In order to decrease measurement error, two versions of the act listings were used. The second version was reverse ordered to reduce the possibility of fatigue and order bias. In addition, each respondent only rated one category of 
acts. The questionnaires were administered in classrooms during class time; we think that this should also have had a positive effect in terms of the amount and quality of attention given by respondents. Finally, a "dummy" act was included in each category (one that was judged by the researchers to be not prototypical). This was used to provide an indication of respondents' understanding of the task.

The sample of judges included a total of 337 students from four separate universities. The program of study for the majority of students was either, 1) arts and science, 2) business administration, or 3) education. Approximately 80 percent of the respondents were undergraduates.

The preliminary analysis required that acts be ranked in order of mean prototypicality rating, in order to highlight the most prototypical acts. Tables 14 contain a summary of the top five, middle five, bottom five and "dummy" act for each construct.

The dummy act in each category has an asterisk beside the rank number. It is encouraging to note that these acts fall in the bottom third of the ranking for all categories. For exit and loyalty, they are ranked 77 th; for voice, 54th and for neglect, 85 th. The low prototypicality rating for these dummy acts suggests that the judges understood what they were rating. The top 25 acts for all categories have means that are greater than the midpoint on the prototypical scale (3.5). These are the acts to be sorted in the third phase.

Table 1

\section{Exit Prototypicality Rankings}

Ranking

1. Quit school for good

$\underline{\text { Mean }}$

2. Decide to quit school

5.46

3. Tell employers you are ready to work into September

5.28

4. Stop going to classes

4.86

5. Tell friends one is thinking of dropping out

4.83

40. Initiate activities that allow one to leave class

4.82

41. Make negative comments about the course

3.28

3.27

42. Socialize with people outside the school

3.23

43. Miss group meetings

3.18

44. Read newspaper in class

3.18

76. Yawn continuously during class

2.57

77. Stay in school at all costs

$2.52^{*}$

78. Change room-mates

2.45

79. Organize students to force program changes

2.33

80. Spread rumours about the professor

2.33

*"dummy" act 
Table 2

Voice Prototypicality Rankings

\section{Ranking}

1. Give comments on course evaluation form

Mean

2. Talk to professor privately about problems

5.55

3. Ask friends for advice on dealing with course problems

5.04

5.00

4. Go to the library when room is too noisy

4.84

5. Ask more questions in class when covering hard material

4.80

40. Take a room-mate to cut costs

3.52

41. Pack up books before class is over

3.48

42. Participate in a demonstration

3.46

43. Become very aggressive

3.46

44. Argue excessively in class discussions

3.42

54. Stop attending class

$3.05 *$

76. Talk disruptively during class

2.15

77. Take out frustrations on professor's secretary

2.12

78. Stomp out of classroom

2.09

79. Cry in private discussions with professor

2.04

80 . Write graffiti about professor on bathroom walls

1.67

*"dummy" act

Table 3

\section{Loyal Prototypicality Rankings}

\section{Ranking}

1. Publicly support the school

Mean

2. Attend all classes

3. Show respect when talking to professor

4. Devote time to extra-curricular activities

5. Pay attention in class

40. Speak with a counsellor

41. Buy people presents that have the university logo or name on them

42. Request changes in course emphasis

43. Seek out others who are in the same situation

44. Criticize disruptive students

76. Send professor a Christmas card

77. Transfer out at the very first chance

78. Ignore professor's sexual advances

79. Recommend to others that they not attend classes

80. Don't report incidence of harassment 
Table 4

Neglect Prototypicality Rankings

Ranking

1. Stop going to class

Mean

2. Don't pull one's weight in groups

5.05

3. Quit caring how well one does

4.96

4. Fail to hand in assignments

4.95

5. Skip classes

4.95

4.86

40. Refuse to join in group activities

4.14

41. Refuse to participate in class discussions

4.13

42. Lie about reasons for being late for assignments

4.13

43. Do not try to change bad situations

4.13

44. Take drugs before class

4.13

81. Lose course outline

2.98

82. Eat too much

2.89

83. Suffer from insomnia

2.83

84. Refuse to leave professor's office until he/she gives a satisfactory answer

2.56

85. Really work hard at assignments

$2.51 *$

*“dummy" act

As with all measure development, it was necessary and important to consider the reliabilities of the ratings. To assess reliability, Cronbach's alpha was calculated for all four constructs. According to Ghiselli et al (1981), Cronbach's alpha is the only appropriate measure of reliability when following a domain sampling approach (or an act-frequency approach). Table 5 presents the reliability results.

Table 5

Reliability Results

\begin{tabular}{lllll}
\hline & Exit & Voice & Loyalty & Neglect \\
Top 25 acts & .91 & .84 & .90 & .94 \\
Top 15 acts & .88 & .78 & .86 & .91 \\
\hline
\end{tabular}

The alpha coefficients for the top 25 acts in each category are all greater than .80. If only the top 15 acts are considered, the alphas drop; however, the minimum alpha across constructs is still .78 (for voice). Although the acceptable value for alpha depends upon the purpose of the research, Nunnally (1967) suggests that reliabilities of .50 to .60 generally suffice. Buss and Craik (1983) find alphas between .77 and .96 for the dispositions they examine. Therefore, the reliability results reported here exceed Nunnally's suggested reliability levels and are comparable to other act-frequency results reported by Buss and Craik. 
As a final check on reliability, the corrected item to total correlation for each act within each construct was reviewed. Churchill (1979) suggests that items with correlations near zero should be eliminated to improve the value of alpha. Although it was possible to increase alpha by selectively deleting items from each of the four scales, the majority of items appeared to be measuring the same common core. Therefore, these items were not deleted and were included in phase 3 .

\section{Phase 3: Multiple Dispositional Act Sorting}

The third phase involves mixing the most prototypical acts associated with different dispositions and inviting a third (and separate) group to sort the acts into the specific disposition categories. In other words, the top 25 acts for each of exit, voice, loyalty and neglect were combined and randomized. Two different classes of undergraduate students were then asked to allocate them to the different EVLN categories. Placement of acts into more than one category was permitted.

The sample included 86 undergraduate students from a fifth university. The purpose of the multiple-dispositional act sorting was to test whether or not prototypical acts could be categorized as expected into the EVLN categories, and to assess the level of agreement on this. This procedure indicates the degree to which the constructs are separate and distinct, that is, the discriminant validity of the instrument. Acts with high percentages in more than one category are considered to be overlapping or "fuzzy" acts. To ensure separability of acts in future research, the fuzzy acts are eliminated from the measure. Tables 6-9 summarize the top 5 acts for each construct.

Table 6

Multi-dimensional Sort Results: Exit

Number of Sorters Classifying Item as Prototypical of Construct $(\%)^{1}$

\begin{tabular}{|c|c|c|c|c|c|c|}
\hline Ranking & $\underline{\mathbf{E}}$ & $\underline{\mathrm{V}}$ & $\underline{\mathrm{L}}$ & $\underline{N}$ & $\underline{E}+\underline{2}$ & $\underline{\text { Other }}^{3}$ \\
\hline 1. Quit school & 80 & 4 & 2 & 8 & 5 & 1 \\
\hline 2. Decide to quite school & 79 & 4 & 1 & 6 & 10 & \\
\hline $\begin{array}{l}\text { 3. Indicate by actions that one } \\
\text { would rather be elsewhere }\end{array}$ & 52 & 26 & 2 & 18 & 1 & 1 \\
\hline $\begin{array}{l}\text { 4. Tell friends one is thinking } \\
\text { of dropping out }\end{array}$ & 52 & 19 & & 6 & 19 & 4 \\
\hline 5. Transfer to a different school & 51 & 27 & 2 & 8 & 10 & 2 \\
\hline
\end{tabular}

E, V, L,N: Exit, Voice, Loyalty and Neglect 1 Percentages are rounded. ${ }^{2}$ Percentage of sorters classifying the item as Exit and either Voice, Loyalty or Neglect. ${ }^{3}$ Percentage of sorters classifying the item as prototypical of a combination of constructs not listed above. 
Table 7

\section{Multi-dimensional Sort Results: Voice}

\section{Number of Respondents Classifying Item as Prototypical of Construct (\%) 4}

$\begin{array}{lllllll}\text { Ranking } & \underline{\mathrm{E}} & \underline{\mathbf{V}} & \underline{\mathrm{L}} & \underline{\mathrm{N}} & \underline{\mathrm{V}^{5}} & \text { Other } \\ \text { 1. Verbally confront others } & & \mathbf{8 6} & 6 & 7 & 1 & \\ \text { 2. Complain to department head } & 2 & \mathbf{8 3} & 5 & 8 & 2 & \\ \text { 3. Talk to room-mates and friends } & & & & & & \\ \quad \text { about problems with professor } & & \mathbf{8 1} & 12 & 6 & 1 & \\ \text { 4. Get rid of bad room-mate } & 5 & \mathbf{7 9} & 2 & 8 & 6 & \\ \text { 5. Appeal marks } & 2 & \mathbf{7 8} & 8 & 8 & 4\end{array}$

E, V, L, N: Exit, Voice, Loyalty and Neglect

4 Percentages are rounded. 5 Percentage of sorters who classified the item as Voice and either Exit Loyalty or Neglect. ${ }^{6}$ Percentage of sorters who classified item as prototypical of a combination of constructs not listed above.

\section{Table 8}

\section{Multi-dimensional Sort Results: Loyalty}

Number of Respondents Classifying the Item as Prototypical of Construct (\%) ${ }^{7}$

Ranking

1. Wear clothing with university

$$
\text { emblem }
$$

2. Publicly support the school

3. Attend all classes

4. Attend class parties

5. Pay attention in class

$\begin{array}{llllll}E & \underline{\mathrm{L}} & \underline{\mathrm{N}} & \underline{\mathrm{L}+} & \underline{\mathrm{Other}}^{9}\end{array}$

$\begin{array}{llllll} & 6 & \mathbf{8 8} & 1 & 5 & \\ & 2 & \mathbf{8 5} & & 12 & 1 \\ 2 & 5 & \mathbf{8 4} & 1 & 8 & \\ & 8 & \mathbf{8 4} & 2 & 6 & \\ 1 & 12 & \mathbf{8 3} & 1 & 3 & \end{array}$

E,V,L,N: Exit, Voice, Loyalty and Neglect

${ }^{7}$ Percentages are rounded. ${ }^{8}$ Percentage of sorters classifying the item as protypical of Loyalty and either Exit, Voice or Neglect. ${ }^{9}$ Percentage of sorters classifying the item as prototypical of a combination of constructs not listed above.

\section{Table 9}

\section{Multi-dimensional Sort Results: Neglect}

Number of Respondents Classifying the Item as Prototypical of Construct (\%) 10

\section{Ranking}

1. Skip group meetings with classmates

2. Hand in assignments without proofreading them

3. Do not expend much effort on assignments

4. Hand in assignments late

5. Fail to make time for doing

$$
\text { course work }
$$

E $\quad \underline{V} \quad \underline{\mathrm{L}} \quad \underline{\mathbf{N}} \quad \underline{\mathrm{N}}^{11}$ Other $^{12}$

$\begin{array}{lllll}2 & 2 & 4 & 88 & 4\end{array}$

$\begin{array}{llllll}2 & 2 & 4 & \mathbf{8 8} & 2 & 2\end{array}$

$\begin{array}{lllll}4 & 3 & 87 & 6\end{array}$

$\begin{array}{lllll}4 & 2 & 5 & 86 & 3\end{array}$

$\begin{array}{llllll}2 & 2 & 4 & 86 & 5 & 1\end{array}$

E,V,L,N: Exit, Voice, Loyalty and Neglect ${ }^{10}$ Percentages are rounded. 11 Percentage of sorters classifying the item as prototypical of Neglect and either Exit, Voice or Loyalty. 12 Percentage of sorters classifying the item as prototypical of a combination of constructs not listed above. 
Based on the results reported in Tables 6 to 9 , raters were able to correctly distinguish between the majority of acts for all constructs except the exit construct. In general, the top twenty-five exit acts were seen as being more typical of 'neglect' than of 'exit' by many sorters. The five most correctly classified exit acts in the sorting phase also had a high degree of overlap with the voice construct. Table 10 summarizes the mean inter-rater agreement across the four constructs for all twenty-five acts, for the best ten acts and for the best five acts, respectively.

Table 10

Mean Inter-rater Rankings (\%)

\begin{tabular}{|c|c|c|c|c|c|}
\hline & Exit & Voice & Loyal & Neglect & Avg. \\
\hline Top 25 Acts & 28 & 60 & 63 & 70 & 56 \\
\hline Best 10 Acts & 52 & 78 & 81 & 85 & 74 \\
\hline Best 5 Acts & 65 & 81 & 85 & 87 & 80 \\
\hline
\end{tabular}

As Table 10 illustrates, the percentage of raters who were able to correctly classify each of the four constructs increases as vague, 'fuzzy' acts are dropped and ratings recalculated on a smaller set. When using only the best 5 acts from each construct, the average number of raters able to correctly classify the acts into their respective categories is $80 \%$ across all four constructs. Similar to Tables 6 to 9 , results reported in Table 10 suggest that the constructs of voice, loyalty and neglect are particularly robust. The results for exit are not as clearcut. However, the fuzzy nature of the exit construct is nevertheless interesting.

What appears to be occurring is a recognition that exit can be either constructive or destructive. On the one hand, raters attributed certain exit acts as behaviours which would hurt themselves. These exit acts were rated as neglectful. Because we defined 'neglect' (on the basis of the nomination phase) to be actions that were dysfunctional to the institution and/or to the student, raters appear to equate many withdrawal acts with dysfunctional actions that primarily impede their own career progression. Examples of these acts include daydreaming in class, missing registration, and skipping classes.

The overlap of some of the nominated exiting behaviors with personal neglect contrasts very sharply with the increasingly popular practice of treating students as customers of a service, in particular the notion that customers simply go elsewhere when not satisfied with an institution's offerings. Clearly, students are more committed to the pursuit of their education than is the normal customer in the pursuit of some service. Equally clearly, the "fuzziness" of the demarcation between exiting and being personally neglectful points to the angst 
many students experience when contemplating withdrawal.

A number of exit acts, on the other hand, were also rated as being quite prototypical of voicing behaviours designed to bring about constructive change. These acts included applying for employment, changing one's student status to part-time studies, taking a semester off or transferring to a different school - all of which were originally nominated as prototypical exit behaviours but which were subsequently sorted into the voice category by a significant number of raters.

That exit can overlap with constructive and destructive behaviours is consistent with recent conceptualizations of the EVLN model posited by Mahaffey and Neu (1988). The distinction between constructive and destructive behaviours is, moreover, consistent with Hirschman's (1970) formulations as well as the work of Farrell (1983) on responses to job dissatisfaction. Nevertheless, this is post hoc speculation. Future research is needed to specifically address why much of what was nominated as exiting behaviour was subsequently sorted as being neglectful or voicing.

\section{The Final Measures}

Phases 1 to 3 identified acts that were both prototypical of EVLN and also discriminated among the four constructs. Table 11 summarizes the top 5 acts from phase 3 for each construct and Table 12 provides summary statistics.

The summary statistics reported in Table 12 suggest that these 20 acts provide viable measures of EVLN. On average, the acts are highly prototypical of the constructs of interest. In addition, the measures appear reliable with an average alpha coefficient of .67. Finally, the acts appear to discriminate among the four constructs. 
Table 11

\section{Final EVLN Acts}

\section{Exit Acts}

1. quit school

2. decide to quit school

3 . indicate by actions that one would rather be elsewhere

4. tell friends one is thinking of dropping out

5. transfer to a different school

\section{Voice Acts}

1. verbally confront others

2. complain to department head

3. talk to room-mates and friends about problems with professor

4. get rid of a bad room-mate

5. appeal marks

\section{Loyal Acts}

1. wear clothing with university emblem

2. publicly support the school

3. attend all classes

4. attend class parties

5. pay attention in class

Neglectful Acts

1. skip group meetings with classmates

2. hand-in assignments without proofreading them

3. do not expend much effort on assignments

4. hand in assignments late

5. fail to make time for doing coursework

Table 12

Summary Statistics

\begin{tabular}{|c|c|c|c|}
\hline & $\begin{array}{l}\text { Mean } \\
\text { Prototypicality }\end{array}$ & $\begin{array}{l}\text { Alpha } \\
\text { Coefficient }\end{array}$ & $\begin{array}{l}\text { Mean Inter- } \\
\text { Rater Ranking }\end{array}$ \\
\hline EXIT & 4.75 & .74 & $65 \%$ \\
\hline VOICE & 4.41 & .57 & 81 \\
\hline LOYAL & 5.18 & .61 & 85 \\
\hline NEGLECT & 4.62 & .76 & $\underline{87}$ \\
\hline TOTAL & 4.74 & .67 & 80 \\
\hline
\end{tabular}




\section{Concluding Comments and Implications for Future Research}

The research reported here has found that a wide range of specific behavioral responses to student dissatisfaction can be classified by more abstract theoretical constructs. Arising out of the seminal work of Hirschman (1970) in political economy, we have labelled these theoretical responses to student dissatisfaction as exit, voice, loyalty and neglect. Furthermore, the domains of these constructs were respondent generated. Based on these results, the groundwork now exists for an integrated examination of student dissatisfaction using the EVLN model. Hopefully this will lead to theories which will predict why some students respond to a given source of dissatisfaction by dropping out, why other students stop going to classes, why some voice their concerns by joining the student government and why others simply work harder.

Measures of exit, voice, loyalty and neglect were developed following the methodology suggested by Buss and Craik $(1983,1985)$ and proponents of the domain sampling approach (Churchill, 1979, Ghiselli et al, 1981). The resulting measures have a high degree of internal consistency; in addition, the majority of measurement items discriminate between the four constructs.

The measurement development process followed here represents an improvement over previous act-frequency studies (cf Block's criticisms, 1989). For example, the measures of EVLN were developed in-context; that is the constructs were developed using university students, at the kind of institution where future research into student dissatisfaction will be conducted. In addition, the use of only the most prototypical acts and acts that can discriminate among constructs mitigates the criticism that ambiguous or unprototypical acts have in the past been included in constructs developed using the AFA (Block, 1989). In other words, the measurement development process followed here results in context-specific constructs, consistent with recent calls for personality-insituation measures (cf Block \& Block, 1981; Block, 1989:237). In addition, the developed measures exhibit the desirable psychometric properties of reliability and discriminant validity.

A number of limitations of the current research deserve comment. The first limitation is methodological. It is our inability to directly address convergent validity. Churchill (1979) among others suggests using the multi-trait multimethod (MTMM) to assess convergent validity. This is not feasible in this case due to there not being a second, independent measure of each of the four constructs. Although this is troubling inasmuch as convergent validity represents the third dimension of construct validity, future empirical research using the four developed measures will provide additional information on their 
convergent validity. Because of the highly visible nature of the majority of nominated behaviours, the possibility of non-intrusive triangulation techniques using external observers is promising.

A second limitation of this research is its scope. While a model which incorporates differential responses to dissatisfaction has now been developed, the task of using the model and measuring the actual frequency of the various responses still lies ahead. The practical value of the current work is therefore limited to its function in building a foundation upon which to add future research. The significance of that research and possible substantive directions it might take are examined next.

It will be recalled that Hirschman's interest lay in the identification of "repairable lapses in an institution's performance" (1970:1), judicious attention to which would prevent further deterioration. Research has begun to document the importance that organizations should attach to these signals of dissatisfaction as well as how these signals (such as EVLN) are inter-connected. According to this research (TARP, 1989), 96\% of dissatisfied clients don't complain; of these, $90 \%$ discontinue their association with the organization if free to do so, and each dissatisfied client tells nine other people. In other words, for each complaint received, 24 other people who are dissatisfied don't complain. If $90 \%$ of non-complainers don't return, the organization loses 22 clients that it didn't even know about for every one complaint received. If each of these 25 dissatisfied clients then tells nine others, they have spread bad news about the organization to 225 people.

Before considering the differences between the context in which these results were obtained, and the context of higher education, it is worth noting two other related research findings. The first finding suggests that word-of-mouth referrals are important in service industries in general (cf. Zeithaml, 1983), and education in particular (cf. Litten, 1989), thus highlighting the significance posed by the negative word-of-mouth in the above illustration. The second finding (cf. Bitner, Booms and Tetrault, 1990) suggests that when organizations deal satisfactorily with voiced dissatisfaction, clients retain highly satisfactory memories of the organization. Combined, this research suggests that dissatisfaction, if untreated, can lead to higher attrition in the short term, and can further snowball with downstream effects on such activities as recruitment and fund-raising; but when dealt with, the negative effects associated with dissatisfaction can largely be mitigated.

These results were found in traditional consumer contexts and not, it needs to be emphasized, in the context of higher education. There are many characteristics of higher education that differ from typical consumption 
situations (Mahaffey, Turner and Buckley, 1989). An important research direction is, therefore, learning the extent to which these findings are replicated in higher education.

A second research direction suggested by these results, is the examination of the effects of friction in higher education on EVLN. Dissatisfied senior year students in multi-year programs may conclude that exit is effectively blocked as a viable alternative. Should the above findings be mirrored in higher education, $96 \%$ of those dissatisfied seniors would not voice. But when faced with blocked exit, would these otherwise non-voicing seniors then choose voice? Among those that refuse voice, would they then choose neglect or loyalty? Under what circumstances these choices are made and in what numbers, are important research questions.

A third research direction is the extension of this work on integrated responses to dissatisfaction to the community college sector. Because of the high occupational focus of many students in this sector (Mahaffey, Turner and Buckley, 1990) it could be hypothesized that college students would exhibit a greater awareness of their "client" status. This awareness in turn, could result in an increased likelihood to voice when that which has been paid for has not been delivered. There may be differences in their tendency to choose among the other EVLN responses, as well.

Regardless of the specific research direction taken, it is hoped that the potential promised by models that integrate alternative responses to dissatisfaction, such as the one proposed here, will lead to increased understanding of the choices that students make.

\section{REFERENCES}

Bitner, Mary Jo; Booms, Bernard M., and Mary Stanfield Tetrault (1990). The service encounter: Diagnosing favorable and unfavorable incidents. Journal of Marketing, 54 (January), $71-84$.

Block, J. (1989). Critique of the Act-Frequency Approach to Personality. Journal of Personality and Social Psychology, 56 (2) : 234-245.

Buss, D. \& Craik, K. (1983). The act frequency approach to personality._Psychological Review, 90 (2) :105-125.

Buss, D. \& Craik, K. (1985). Why not measure that trait? Alternative criteria for identifying important dispositions. Journal of Personality and Social Psychology, 48 (4): 934-946.

Churchill, G.A. Jr. (1979). A paradigm for developing better measures of marketing constructs. Journal of Marketing Research, 16 :64-73. 
Cullers, B., Hughes, C., and McGreal, T. (1973). Administrative behavior and student dissatisfaction: A possible relationship. Peabody Journal of Education, 50(2):155163.

Diener, T. (1973). Can the student voice help improve teaching? Improving College and University Teaching, 21(1):35-37.

Farrell, Dan (1983). Exit, Voice, Loyalty and Neglect as Responses to Job Dissatisfaction: A Multidimensional Scaling Study. Academy of Management Journal, 26(4):596-607.

Ghiselli, E., Campbell, J., \& Zedeck, S. (1981). Measurement theory for the behavioral sciences. San Francisco, CA: WH Freeman \& Company.

Hirschman, A. (1970). Exit, voice and loyalty: Responses to decline in firms, organizations and states. Cambridge, MA: Harvard University Press.

Litten, Larry H. and Alfred E. Hall (1989). In the eyes of our beholders. Journal of Higher Education, (May-June), 302-324.

Mahaffey, T. and Neu, D. (1988). EVLN: Responses to Employee Dissatisfaction in the 1990s. Proceedings of the 1988 Annual Conference of the Atlantic Schools of Business.

Mahaffey, T., Turner, Ronald E., and Patrick G. Buckley (1989). An Exploratory Analysis of Service Quality in the Selection of an Educational Institution. Paper presented to the Atlantic Schools of Business Conference, Dalhousie University.

Mahaffey, T., Turner, Ronald E., and Patrick G. Buckley (1990). Quality of Adult Education: From the Learner's Perspective. Proceedings of the Canadian Association for Studies in Adult Education.

Nunnally, J. (1967). Psychometric theory. New York, NY: McGraw-Hill.

Rosch, E. (1975). Cognitive representations of semantic categories. Journal of Experimental Psychology General, 104:192-223.

Rosch, E., and Mervis, C.B., (1975). Family Resemblances. Studies in the internal structure of categories. Cognitive Psychology, 7 :573-605.

Rusbult, C., \& Zembrodt, I. (1983). Responses to dissatisfaction in romantic involvements: A multi-dimensional scaling analysis. Journal of Experimental Social Psychology, $19: 274-293$.

Rusbult, C., Zembrodt, I., \& Gunn, L. (1982). Exit, voice, loyalty and neglect: Responses to dissatisfaction in romantic involvements. Journal of Personality and Social Psychology, 43 : 1230-1242.

Steele, M. (1978). Correlates of undergraduate retention at the University of Miami. Journal of College Student Personnel, 19 :349-352.

TARP (1989). Technical Assistance Research Program. Office of Special Advisor to the President. Washington, D.C.

Thorndike, R. (1971). Educational Measurement. Washington, DC:American Council on Education.

Tinto, V. (1975). Dropout from higher education: A theoretical synthesis of recent research. Review of Educational Research, 45(1):89-125. 
89 Exit, Voice, Loyalty and Neglect as Student Responses to Dissatisfaction

Withey, M. (1986). Exit, voice, loyalty and neglect: Employee responses to declining satisfaction. Unpublished doctoral dissertation, Queen's University, Kingston.

Withey, M. \& Cooper, W. (1989). Predicting exit, voice, loyalty and neglect. Administrative Sciences Quarterly, 34, 521-39.

Zadeh, L.A., Fu, K. S., Tanaka, K., and Shimura, M. (eds.) (1975). Fuzzy sets and their applications to cognitive and decision processes. New York: Academic Press.

Zeithaml, Valerie (1983). How consumer evaluation processes differ between goods and services. In Marketing of Services, ed. J.H. Donnelly and W. R. George. Chicago: American Marketing Association. 